\title{
Práticas de Inclusão Digital na Educação de Jovens e Adultos: minicurso de Introdução à Informática
}

\author{
Rafael da Silva da Cunha ${ }^{1}$, Rita Diana de Freitas Gurgel ${ }^{1}$ \\ ${ }^{1}$ Universidade Federal Rural do Semi-Árido (UFERSA) \\ Caixa Postal 59515-000 - Angicos - RN - Brasil \\ rafael_ufersa@hotmail.com, rdiana@ufersa.edu.br
}

\begin{abstract}
The integration of Information and Communication Technologies (TIC) in society caused considerable changes in various sectors. In this scenario, it is necessary for people to follow the development and be able to use these technologies significantly. However, even with the expansion in recent years, some groups have no access to or do not know how to use TIC, becoming digital excluded. Thus, it is necessary that digital inclusion practices are developed aiming the integration of these groups in this new model of society. In the Youth and Adult Education (EJA) these actions have greater importance, with a view that will contribute to social inclusion of the public. In this perspective, subproject members of Computing and Informatics of the PIBID/UFERSA developed a short course for introductory computing with students of EJA of an Angicos/RN municipal school. The short course was attended by 15 participants, who had classes about operating systems (Windows), Office package (Word and PowerPoint) and Internet. During the intervention, the students presented some difficulties which were subsequently overcome. At the end of the short course, participants said they obtained knowledge about the use of technology worked and that they will contribute to their social and professional integration. Finally, we concluded that the experiment was successful in promoting digital inclusion of students of adult education.
\end{abstract}

Resumo. A integração das Tecnologias da Informação e Comunicação (TICs) na sociedade provocou mudanças consideráveis nos mais diversos setores. Neste cenário, é preciso que as pessoas acompanhem o desenvolvimento e estejam aptas a utilizarem estas tecnologias de forma significativa. Entretanto, mesmo com a expansão dos últimos anos, alguns grupos não possuem acesso ou não sabem utilizar as TICs, tornando-se excluídos digitais. Dessa forma, torna-se necessário que práticas de inclusão digital sejam desenvolvidas objetivando a integração destes grupos neste novo modelo de sociedade. $\mathrm{Na}$ Educação de Jovens e Adultos (EJA) estas ações apresentam maior importância, tendo em vista que irão contribuir para a inclusão social deste público. Nessa perspectiva, integrantes do subprojeto Computação e Informática do PIBID/UFERSA desenvolveram um minicurso de introdução à computação com educandos da EJA de uma escola municipal de Angicos/RN. $O$ minicurso contou com 15 participantes, que tiveram aulas sobre Sistemas Operacionais (Windows), Pacote Office (Word e PowerPoint) e Internet. Durante a aplicação dos conteúdos, os educandos apresentaram algumas dificuldades que foram posteriormente superadas. Ao término do minicurso, os participantes afirmaram terem obtido os conhecimentos acerca da utilização das tecnologias trabalhadas e que estes irão contribuir para sua integração social e profissional. Ao final, concluiu-se que a experiência se mostrou exitosa 
V Congresso Brasileiro de Informática na Educação (CBIE 2016)

Anais do XXII Workshop de Informática na Escola (WIE 2016)

na promoção da inclusão digital dos educandos da EJA.

\section{Introdução}

As Tecnologias da Informação e Comunicação (TICs) se fazem cada vez mais presentes na sociedade, provocando mudanças nos mais diversos setores e trazendo novas possibilidades informacionais, comunicacionais e cognitivas. A incorporação destas no cotidiano social, exige das pessoas conhecimentos e habilidades acerca de sua utilização, tendo em vista que, atividades rotineiras como uma simples consulta bancária, tornam-se desafiadoras quando o indivíduo não está familiarizado com as tecnologias. Dessa forma, nos dias atuais, é imprescindível que além do ler e escrever, as pessoas possuam noções básicas de informática e acesso às TICs.

Entretanto, mesmo com o processo de expansão das novas TICs, impulsionado pelo surgimento e popularização do computador e da internet, ainda há uma grande quantidade de pessoas que se encontra despreparada para o manuseio ou que não possuem acesso a tais ferramentas. Criam-se então duas novas classes de pessoas, os chamados incluídos digitais e os excluídos digitais. Sendo assim, tornam-se necessárias ações que viabilizem à inclusão digital desses indivíduos.

O termo Inclusão Digital se refere à democratização das tecnologias da informação, com a intenção de garantir o acesso de todas as pessoas, independentemente da condição econômica. Trata-se de não apenas promover o contato do homem com as máquinas e introduzir conhecimentos informáticos, é preciso que tais conhecimentos façam sentido para os indivíduos, e as informações sejam compreendidas e transformadas em conhecimentos novos, contribuindo consequentemente para a melhoria da qualidade de vida das pessoas, no âmbito pessoal e profissional. Nesta perspectiva, incluir digitalmente uma pessoa ocasionará maiores possibilidades de sua inclusão social, haja vista a incorporação das TICs pela sociedade.

Vale salientar, que as instituições de ensino exercem fundamental importância neste processo e precisam promover ações efetivas que viabilizem a inclusão digital de seus educandos. Na Educação Infantil, Ensino Fundamental I e II e Ensino Médio isto acontece com maior frequência, já que crianças e adolescentes fazem parte dos chamados nativos digitais, pessoas que nasceram e cresceram nessa nova era tecnológica, tornandose muito mais fácil conviver com TICs, e manuseá-las de forma significativa.

Em contrapartida, na Educação de Jovens e Adultos (EJA), modalidade de ensino composta por educandos que por suas condições históricas de exclusão não tiveram formação escolar na idade certa, este processo acontece lentamente e carece de uma maior atenção. Os integrantes deste público, já excluídos socialmente por não saberem ler e escrever, mediante o surgimento das TICs tornam-se também, excluídos digitais. Desse modo, promover o acesso e a utilização significativa das tecnologias, lhes possibilitará desenvolver habilidades e competências que contribuirão para a aprendizagem e para uma melhor integração social. Sendo assim, práticas de inclusão digital na EJA, tornam-se necessárias e altamente relevantes.

Neste prisma, o Programa Institucional de Bolsas de Iniciação à Docência (PIBID), da Universidade Federal Rural do Semi-Árido (UFERSA), através do Subprojeto Computação e Informática, vem promovendo práticas de inclusão digital nas escolas de Angicos/RN, cidade na qual se encontra situado o campus universitário.

Dentre estas ações, destaca-se aqui a elaboração e aplicação de um minicurso de 
V Congresso Brasileiro de Informática na Educação (CBIE 2016)

Anais do XXII Workshop de Informática na Escola (WIE 2016)

Introdução à Informática com educandos da EJA de uma escola pública municipal de Angicos/RN. O principal objetivo do minicurso foi promover a inclusão digital dos educandos da EJA, através de aulas teórico-práticas acerca da Inicialização do Computador (Ligar/Desligar), Sistemas Operacionais (Introdução ao Windows), Pacote Office (Word e PowerPoint) e Internet. Antes da efetivação da proposta, buscou-se conhecer o perfil dos participantes, assim como seus conhecimentos informáticos.

Assim sendo, o presente trabalho constitui-se como um relato de experiência da ação supracitada. Serão tratadas aqui, concepções de autores quanto ao processo de inclusão digital de jovens e adultos, bem como apresentado uma análise dos resultados obtidos, destacando as dificuldades encontradas durante a realização do minicurso e as contribuições para a inclusão digital dos educandos participantes.

\section{Inclusão Digital na EJA: um caminho para a inclusão social}

A Educação de Jovens e Adultos é uma modalidade de ensino da Educação Básica prevista pela Lei de Diretrizes e Bases da Educação Nacional (LDB - Lei nº 9.394/96), que tem como objetivo contribuir para a erradicação do analfabetismo da população de jovens e adultos que não tiveram acesso à educação escolar na faixa etária apropriada, nem obtiveram sucesso na conclusão do Ensino Fundamental ou do Ensino Médio.

A EJA apresenta uma estrutura diferenciada de ensino, com carga horária reduzida, já que grande parte dos educandos desta modalidade concilia trabalho e estudos, este último quase sempre posto em segundo plano (MIRANDA; MACHADO, 2010). O público da EJA é bastante diversificado e as turmas, quase sempre são compostas por jovens, adultos e idosos em diferentes faixas etárias.

Quanto ao perfil do educando da EJA, Gadotti (2008, p.31) afirma que "os jovens e adultos trabalhadores lutam para superar suas condições precárias de vida (moradia, saúde, alimentação, transporte, emprego, etc.) que estão na raiz do problema do analfabetismo". Percebe-se então, que estes educandos se encontram normalmente em situação de vulnerabilidade econômica, sentem-se discriminados, oprimidos e excluídos socialmente e procuram superar todas essas dificuldades através da educação.

De acordo com Freire (2006, p. 19), a EJA se caracteriza como "um ato político e um ato de conhecimento, por isso mesmo, um ato criador", no qual o educando busca uma mudança de vida, que vai além da aprendizagem do conteúdo escolar. Esta mudança "parte da necessidade de superar a situação opressora. Isto implica no reconhecimento crítico, na razão desta situação, para que, através de uma ação transformadora que incida sobre ela, se instaure outra, que possibilite aquela busca do ser mais" (FREIRE, 1987, p.17). Nota-se, portanto, a importância da alfabetização como início de um processo de participação social como direito de cidadania (GADOTTI, 2008).

Nesse contexto, a inclusão digital na EJA configura-se como um caminho que dará maiores possibilidades de inclusão social destes jovens e adultos. Conforme aponta Lèvy (2001, p.51), "o ciberespaço será o centro das atividades econômicas, culturais e sociais, tendo a Internet como vetor de reorganização da sociedade que surge para além da cidade física". Portanto, é necessário que todas as pessoas estejam preparadas para atuar neste novo modelo de sociedade, se apropriando dos recursos tecnológicos em suas atividades pessoais e profissionais.

$\mathrm{Na}$ atualidade, o acesso às TICs está diretamente relacionado aos direitos dos indivíduos à informação e a liberdade de expressão. Para tanto, iniciativas de inclusão 
digital são necessárias para a extinção das diferenças sociais existentes. Entretanto, é importante destacar que incluir uma pessoa digitalmente, não significa apenas colocá-lo em contato com ferramentas tecnológicas. Ter ou não acesso as ferramentas tecnológicas é apenas um dos muitos fatores que influenciam a inclusão/exclusão digital, porém não é o único, nem o mais relevante (BONILLA, 2001; SILVA, 2002), tendo em vista, que mais importante que o acesso propriamente dito, é sua utilização de forma significativa.

Contudo, Gomes (2002) evidencia que se tornou essencial a inclusão da informática e dos demais saberes tecnológicos na vida das pessoas, seja por meio de cursos, estratégias sócio-políticas, mas, principalmente nas atuações nas escolas, já que o objetivo desta é preparar o educando para agir em sociedade. Sendo assim, práticas de inclusão digital, possibilitarão o desenvolvimento de uma inteligência coletiva, além de contribuir para uma melhor qualidade de vida dos indivíduos, oferecendo-lhes condições igualitárias para a busca de novas oportunidades profissionais e consequentemente um aumento na renda salarial e uma maior integração social (GULO, 2011).

\section{Materiais e Métodos}

A experiência aqui apresentada foi desenvolvida por um grupo de bolsistas integrantes do Subprojeto Computação e Informática do PIBID/UFERSA. Foram ofertadas 20 vagas para o minicurso de Introdução à Informática para educandos da EJA de uma escola municipal de Angicos/RN parceira do programa. Antes do período de inscrição, realizaram-se visitas nas turmas, apresentando o minicurso e distribuindo folhetos explicativos.

As inscrições aconteceram durante dois dias na escola parceira. Entretanto, somente 15 educandos fizeram a inscrição. Achou-se necessário, antes de realizar o minicurso, aplicar um questionário buscando conhecer o perfil dos educandos inscritos, bem como questões acerca do acesso ao computador e à internet e das dificuldades na utilização dos recursos informáticos.

O minicurso foi planejado com uma carga horária de 24 horas e dividido em três módulos, sendo eles: Inicialização do Computador (Ligar/Desligar) e Sistemas Operacionais (Introdução ao Windows); Pacote Office (Word e PowerPoint); e por fim o módulo Internet. Para acompanhamento do conteúdo por parte dos educandos, foi desenvolvido um material didático, entregue de forma impressa, no início de cada encontro. Como método avaliativo da eficácia do minicurso, optou-se por realizar atividades práticas que exigiam dos participantes o conhecimento dos conteúdos ministrados.

Após o término do conteúdo planejado, foi aplicado novamente um questionário com os participantes, pretendendo-se analisar as contribuições do minicurso para a aprendizagem e o nível de satisfação destes quanto às aulas ministradas e à atuação dos bolsistas. Os dados obtidos nos questionários receberam tratamento estatístico para uma melhor apreciação dos resultados.

\section{Resultados e Discussões}

\subsection{Conhecendo os participantes do minicurso}

Dos 15 educandos da EJA que efetuaram a inscrição no minicurso, 60\% eram do gênero feminino, enquanto $40 \%$ pertenciam ao gênero masculino, conforme Gráfico 1. 
V Congresso Brasileiro de Informática na Educação (CBIE 2016)

Anais do XXII Workshop de Informática na Escola (WIE 2016)

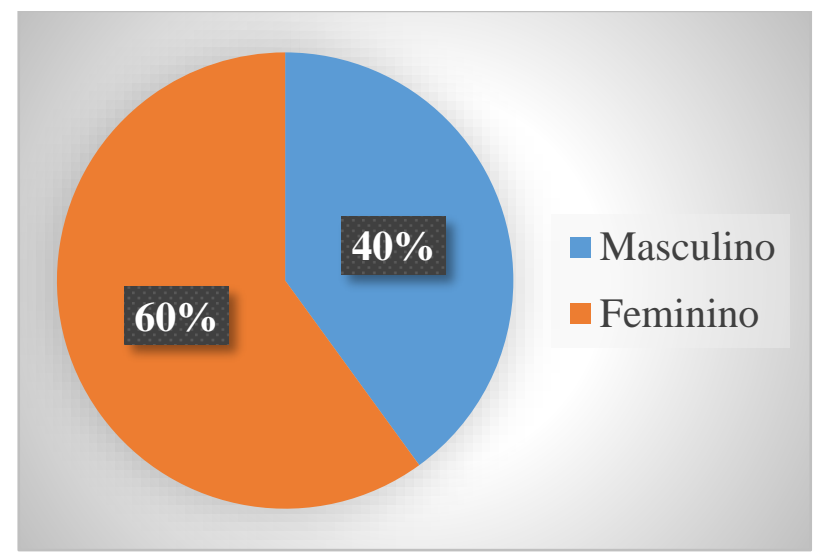

Gráfico 1: Gênero

O Gráfico 2 apresenta a faixa etária dos educandos, no qual observa-se que $93 \%$ tem idades que variam de 15 a 20 anos. Portanto, é possível constatar que o público da EJA atendido pelo minicurso é um público jovem, que, por estarem desnivelados optaram por esta modalidade de ensino. Verificou-se ainda que foram atendidos educandos da EJA, correspondente ao Ensino Fundamental II, sendo a maioria destes do $9^{\circ}$ ano.

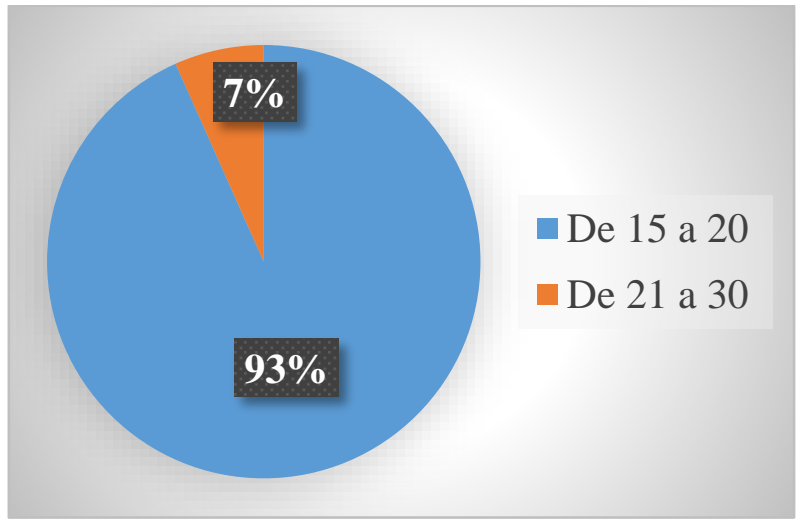

Gráfico 2: Faixa etária

Como o minicurso iria tratar dos conteúdos diretamente relacionados ao uso do computador, buscou-se saber se os participantes possuíam tal ferramenta. Como mostra o Gráfico 3, 60\% disse não possuir.

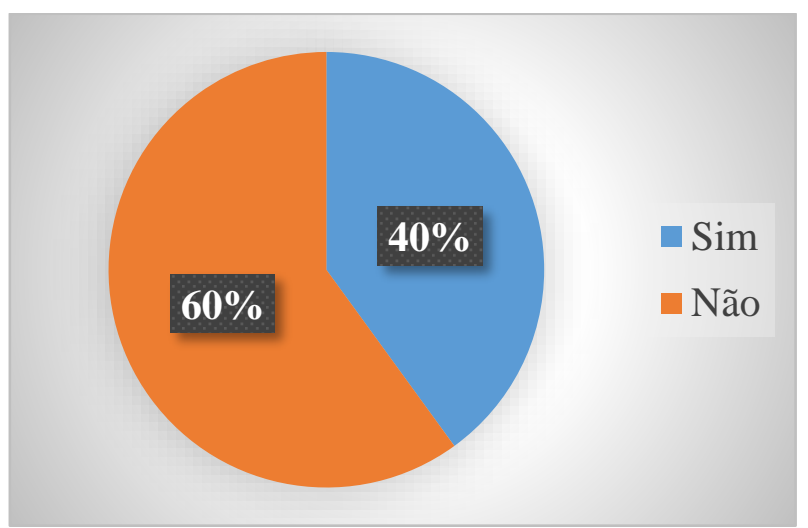

Gráfico 3: Possui computador

Quanto à frequência de uso do computador e da internet, identificou-se que $60 \%$ dos educandos usam pouco estas tecnologias e 13\% não as utilizam (Gráfico 4). Nota-se então que, grande parte dos inscritos no minicurso pertencem ao grupo dos excluídos 
V Congresso Brasileiro de Informática na Educação (CBIE 2016)

Anais do XXII Workshop de Informática na Escola (WIE 2016)

digitais. Questionou-se ainda se estes não utilizam as TICs na escola e todos afirmaram que não.

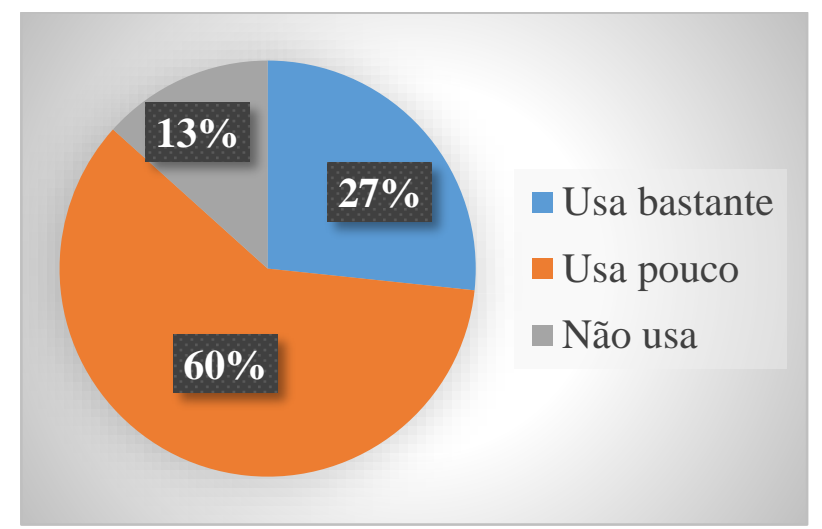

\section{Gráfico 4: Frequência de uso do computador e da internet}

Por último, objetivou-se identificar se os educandos inscritos possuíam dificuldades acerca da utilização dos recursos informáticos, principalmente dos conteúdos que iriam ser abordados no minicurso. Como aponta o Gráfico 5, 80\% disseram enfrentar dificuldades, justificando-se assim, a realização da ação aqui apresentada.

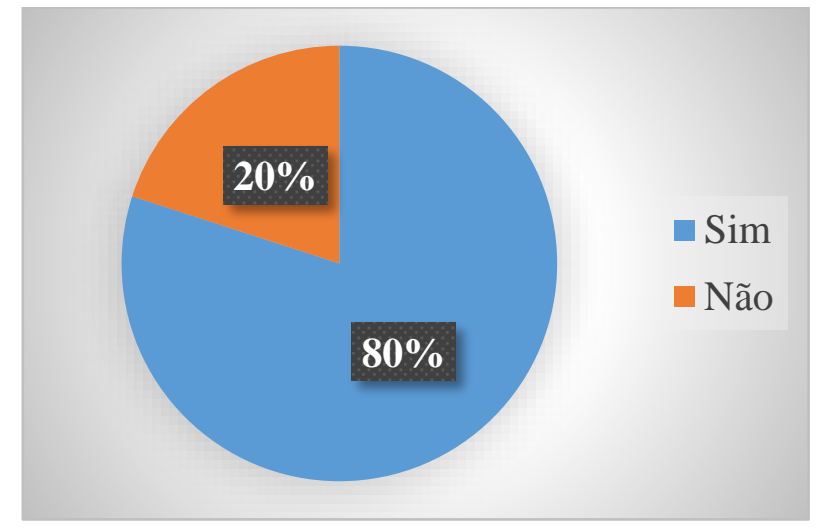

Gráfico 5: Sentem dificuldades na utilização de recursos informáticos

\subsection{O minicurso de Introdução à Informática na EJA}

O minicurso foi realizado no laboratório de informática da UFERSA/Campus Angicos, nas tardes de sábado, tendo em vista que alguns dos inscritos trabalham durante a semana. Foi disponibilizado o ônibus circular da UFERSA para fazer o translado dos alunos até o campus. No geral, aconteceram 6 encontros, sendo que o último foi apenas para certificação dos participantes e confraternização entre os envolvidos. Em cada encontro, havia pelo menos 5 bolsistas atuando, 1 conduzindo os conteúdos e os outros oferecendo suporte aos participantes.

Na primeira aula foi feita uma explanação sobre a importância dos conhecimentos tecnológicos para a inclusão social e profissional das pessoas. Os educandos participaram da discussão e disseram compreender a necessidade do domínio das tecnologias nessa nova sociedade que se instaurou. Em seguida, foi orientado quais os procedimentos para ligar e desligar um computador; pediu-se então, que os participantes ligassem suas máquinas. Poucos tiveram dificuldade nessa etapa.

Ainda no mesmo encontro, iniciou-se o conteúdo sobre Sistemas Operacionais (SO), com ênfase no Windows 7. Inicialmente, foi explicado quais as funções do SO, e 
V Congresso Brasileiro de Informática na Educação (CBIE 2016)

Anais do XXII Workshop de Informática na Escola (WIE 2016)

sua fundamental importância no gerenciamento do computador. Após este momento, foi orientado que os participantes fossem fazendo em seus computadores o que o bolsista monitor estava explicando, e acompanhando também o material didático que foi disponibilizado. O conteúdo trabalhado no módulo SO, encontra-se na Tabela 1.

\section{Tabela 1: Conteúdos trabalhados no módulo Sistemas Operacional - Windows}

\begin{tabular}{|l|l|l|}
\hline Introdução & Janelas & Renomear uma pasta \\
\hline Iniciando o Windows & Salvando arquivos & Copiar, recortar e colar arquivos \\
\hline Área de trabalho & Meu computador & Aparência do Windows \\
\hline Ícones & Windows Explorer & Lixeira do Windows \\
\hline Barra de tarefas & Exibir o conteúdo de uma pasta & Esvaziando a lixeira \\
\hline O botão iniciar & Criar nova pasta & Desligando o Windows \\
\hline
\end{tabular}

Durante o desenvolvimento da aula, os bolsistas estavam observando os educandos e ajudando diante de suas dificuldades. Alguns enfrentavam problemas no manuseio do mouse, que aos poucos foram sendo superados. O módulo sobre sistemas operacionais durou dois encontros.

No final do segundo encontro, após a conclusão dos conteúdos de SO, teve início o módulo referente ao Pacote Office (Word e PowerPoint). O Word foi o primeiro a ser trabalhado, e os conteúdos podem ser vistos na Tabela 2. Neste módulo os educandos tiveram um pouco de dificuldade, principalmente na digitação e formatação de textos, mas, aos poucos, foram se aperfeiçoando. Ao término dos conteúdos, no terceiro encontro, orientou-se uma atividade utilizando o software estudado, que foi executada por todos os participantes.

Tabela 2: Conteúdos trabalhados no módulo Pacote Office - Word

\begin{tabular}{|l|l|l|}
\hline Introdução & Janelas & Renomear uma pasta \\
\hline $\begin{array}{l}\text { Conhecendo a tela } \\
\text { inicial }\end{array}$ & Recortar, copiar e colar texto & Localizar e substituir texto \\
\hline $\begin{array}{l}\text { Iniciar um novo } \\
\text { documento }\end{array}$ & Fonte, tamanho e cor da fonte & Ortografia e gramática \\
\hline Salvar um documento & Estilos negrito, itálico e sublinhado & Inserindo símbolos \\
\hline $\begin{array}{l}\text { Abrir e Fechar um } \\
\text { documento }\end{array}$ & Alinhamento do texto & Inserindo imagens \\
\hline Selecionar texto & Desfazer e refazer alterações & Texto em colunas \\
\hline
\end{tabular}

No quarto encontro, foi o momento de trabalhar o software PowerPoint com os educandos. Como também pertence ao Pacote Office da Microsoft, a interface do programa é bem parecida com a do Word; sendo assim, a adaptação dos alunos foi mais rápida e os mesmos conseguiram acompanhar o conteúdo (Tabela 3) sem muitos problemas. Nesta etapa, também foi solicitado uma atividade como forma de avaliação da aprendizagem. Individualmente, os participantes do minicurso escolheram um tema e elaboraram suas apresentações em slides. Estas em sua maioria estavam de acordo com o que se pediu.

Tabela 3: Conteúdos trabalhados no módulo Pacote Office - PowerPoint

\begin{tabular}{|l|l|}
\hline Introdução & Abrindo uma apresentação existente \\
\hline Conhecendo a tela inicial & Inserindo imagens, músicas e vídeos \\
\hline $\begin{array}{l}\text { Iniciar uma nova } \\
\text { apresentação }\end{array}$ & Fonte, tamanho e cor da fonte \\
\hline Salvar uma apresentação & Usando modelos \\
\hline Layout do slide & Efeitos de transição \\
\hline Trabalhando com tópicos & Controlando os tempos de exibição \\
\hline
\end{tabular}


O último módulo trabalhado no minicurso foi o de Internet. Tratou-se neste encontro sobre mecanismos de pesquisa, criação de e-mails e redes sociais. Verificou-se que $60 \%$ dos educandos já possuíam contas em redes sociais e em serviços de e-mail, e as utilizam pelo celular. Mesmo assim, foi apresentado um tutorial de criação de cadastros nestes serviços. Tratou-se também sobre pesquisas em sites e download de vídeos no YouTube.

O sexto encontro e último encontro foi o momento de entrega dos certificados de participação no minicurso. Os educandos mostraram-se realizados em terem chegado até o fim das atividades e afirmaram que os conhecimentos adquiridos irão contribuir para a realização de atividades escolares, para entretenimento e para o futuro profissional.

\subsection{Avaliação do minicurso por parte dos educandos da EJA}

Com o término do minicurso, foi aplicado um questionário com os participantes, para que estes pudessem avaliar a ação. De acordo com o Gráfico 6, 87\% dos educandos avaliaram o minicurso como ótimo e $13 \%$ como bom. Verifica-se então que estes ficaram satisfeitos com a atividade executada.

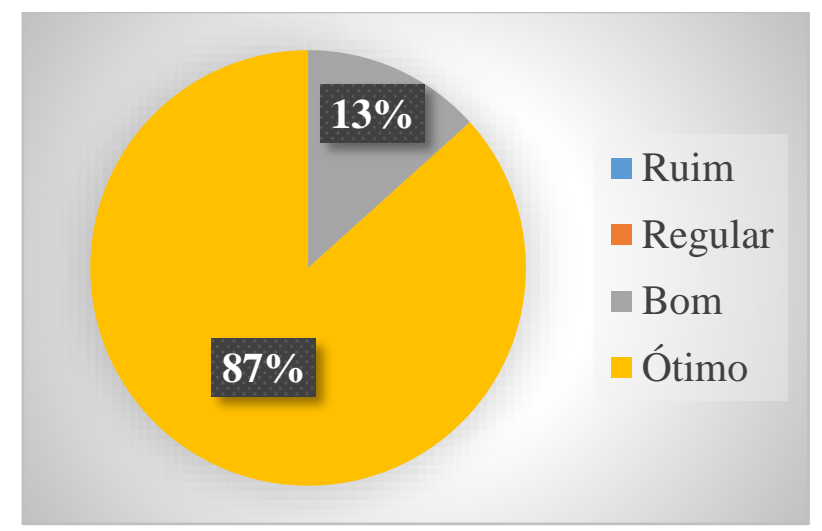

\section{Gráfico 6: Avaliação do minicurso por parte dos educandos}

Quanto à autoavaliação da aprendizagem, 87\% afirmaram terem obtido integralmente os conhecimentos a partir dos conteúdos trabalhados e 13\% parcialmente, conforme Gráfico 7.

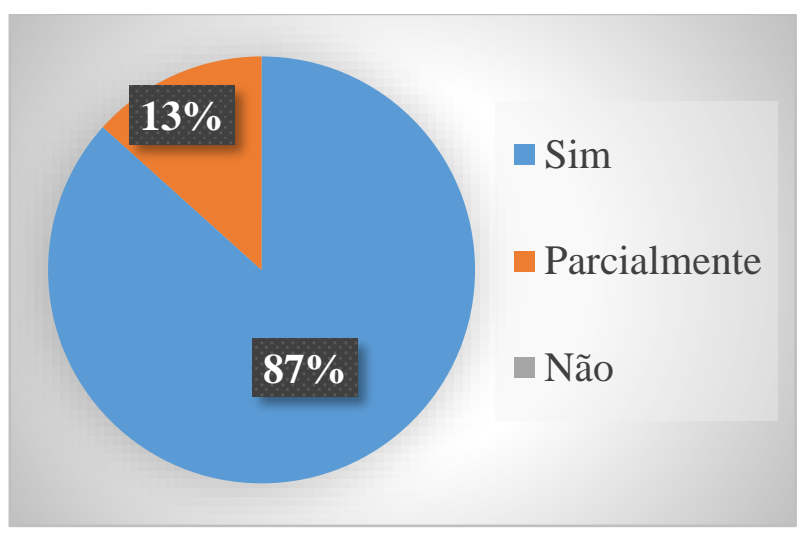

Gráfico 7: Conseguiram obter conhecimentos com o minicurso

Da mesma forma, no Gráfico 8, observa-se que 53\% dos participantes avaliam seus conhecimentos em informática após o minicurso como ótimo, seguidos por bom $(34 \%)$ e regular $(13 \%)$. 
V Congresso Brasileiro de Informática na Educação (CBIE 2016)

Anais do XXII Workshop de Informática na Escola (WIE 2016)

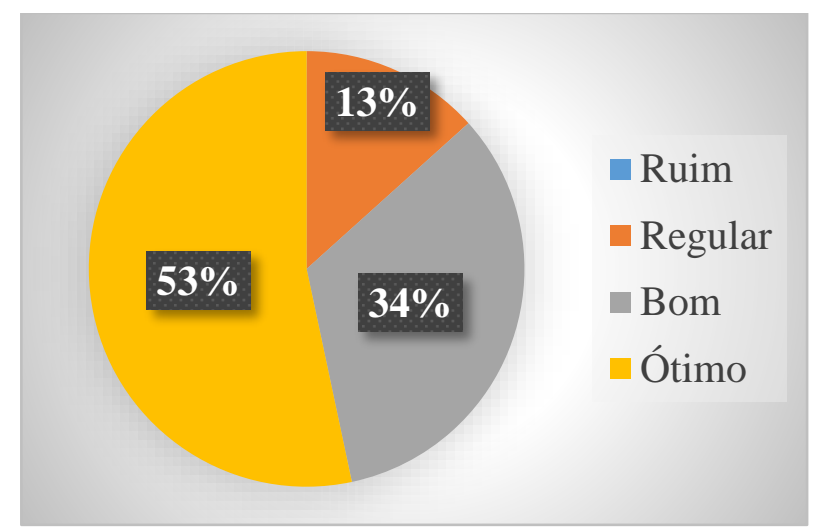

Gráfico 8: Autoavaliação após o minicurso

Por fim, em relação a atuação dos bolsistas no minicurso, $60 \%$ dos educandos avaliaram como ótima, 33\% como bom e 7\% regular, como observado no Gráfico 9.

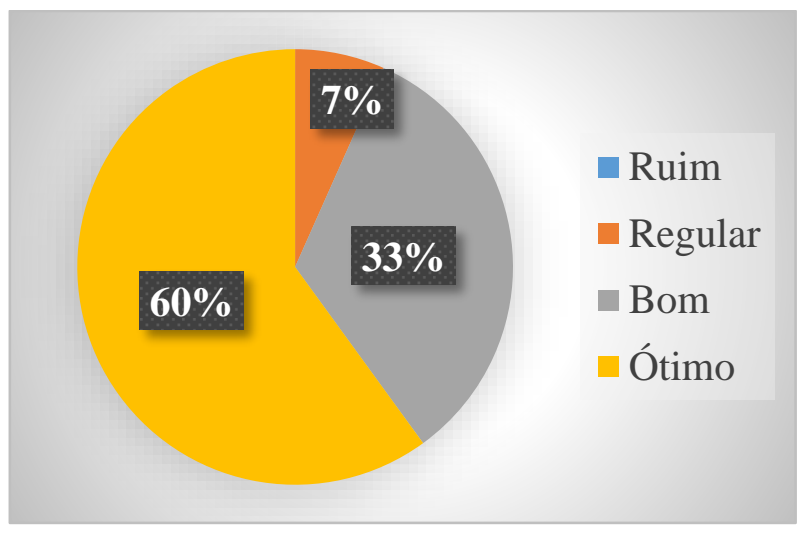

Gráfico 9: Avaliação da atuação dos bolsistas

\section{Considerações finais}

A inclusão digital na EJA apresenta-se como um importante mecanismo de inclusão social. Nesse sentido, práticas de inclusão digital de jovens e adultos tornam-se necessárias e a escola assume importante responsabilidade neste processo. A partir dessa constatação, o Subprojeto Computação e Informática do PIBID/UFERSA promoveu um minicurso de Introdução à Informática com educandos da EJA de Angicos/RN.

O público atendido era na sua maioria formado por mulheres, com idades que variavam entre 15 e 20 anos. Dos participantes, 60\% disseram não possuir computador e $80 \%$ enfrentam dificuldades na utilização de ferramentas informáticas. Justificou-se, portanto, a realização do minicurso como ação de promoção da inclusão digital de jovens e adultos.

Durante as aulas, os participantes conseguiram acompanhar os conteúdos, incialmente com dificuldades, que foram sendo superadas. As atividades avaliativas propostas foram desenvolvidas da maneira orientada, compreendendo-se, portanto, a efetividade da metodologia adotada. Dos 15 inscritos, todos conseguiram concluir o minicurso, não sendo registrada nenhuma desistência. Além disso, afirmaram de forma unânime terem obtidos conhecimentos a partir dos conteúdos trabalhados. Quanto a seus conhecimentos em informática após o minicurso, 53\% consideraram como ótimos.

Contudo, pode-se concluir que o minicurso de Introdução à Informática na EJA conseguiu obter seu objetivo, na medida em que contribuiu para a aprendizagem dos 
V Congresso Brasileiro de Informática na Educação (CBIE 2016)

Anais do XXII Workshop de Informática na Escola (WIE 2016)

educandos e desenvolveu nestes, habilidades no manuseio de recursos tecnológicos. A inclusão digital acontece quando o indivíduo utiliza a tecnologia de forma significativa, encontrando um sentido para esta utilização e construindo conhecimento a partir dela. Nota-se então que a experiência relatada conseguiu plantar esta semente com os alunos da EJA. Por fim, ressalta-se a importância de ações desta natureza na EJA, modalidade de ensino carente de projetos que visem a integração social.

\section{Referências}

BONILLA, M. H. (2001) O Brasil e a alfabetização digital. Jornal da Ciência, Rio de Janeiro, p.7. Disponível em: <http://www.faced.ufba.br/ bonilla/artigojc.htm>. Acesso em: dez. 2015.

FREIRE, P. (2006) A importância do ato de ler: em três artigos que se completam. 47.ed. São Paulo: Cortez.

FREIRE, P. (1987) Pedagogia do oprimido. 17. ed. Rio de Janeiro: Paz e Terra.

GADOTTI, M. (2008) MOVA, por um Brasil Alfabetizado. São Paulo: Instituto Paulo Freire. Disponível em: <http://www.acervo.paulofreire.org:8080/xmlui/bitstream/handle/7891/3084/FPF_PT PF_12_081.pdf >. Acesso em: out. 2015.

GADOTTI, M.; ROMÃO, J. E. (Orgs.). (2008) Educação de Jovens e Adultos: Teoria, Prática e Proposta. 10. ed. São Paulo: Cortez: Instituto Paulo Freire.

Gomes, N.G. (2002). Computador na escola: novas tecnologias e inovações educacionais. In: BELLONI, M. L. (Org.). A formação na sociedade do espetáculo. p. 119-134. São Paulo: Loyola.

GULO, C. et al. (2011) Utilizando GCompris na Escola. In: II ENCONTRO NACIONAL DE INFORMÁTICA E EDUCAÇÃO ENINED 2011, Cascavel. Anais... Cascavel, PR: [s.n.], p. 225-264.

LÉVY, P. (2001) A conexão planetária: o mercado, o ciberespaço e a consciência. São Paulo: Editora 34.

MIRANDA, M.; MACHADO, R. (2011) Uma proposta de inclusão digital com alunos da educação de jovens e adultos. In: II SEMINÁRIO DE PESQUISA DA NUPEPE 2011, Uberlândia. Anais... Uberlândia, MG: p. 532-544.

SILVA, J. B. G. (2002) Alfabetização tecnológica: alguns aspectos práticos. Boletim EAD, Campinas, n. 41. 